OPEN ACCESS

Edited by:

Jeanette M. Norton, Utah State University, United States

Reviewed by:

Xuesong Luo,

Huazhong Agricultural University,

China

Xiao-Jun Allen Liu, University of Massachusetts Amherst, United States

${ }^{*}$ Correspondence: Pil Joo Kim pjkim@gnu.ac.kr

Specialty section:

This article was submitted to Terrestrial Microbiology, a section of the journal

Frontiers in Microbiology

Received: 30 August 2019 Accepted: 09 December 2019 Published: 20 December 2019

Citation:

Das S, Lee JG, Cho SR, Song HJ and Kim PJ (2019) Silicate Fertilizer Amendment Alters Fungal Communities and Accelerates Soil Organic Matter Decomposition. Front. Microbiol. 10:2950. doi: 10.3389/fmicb.2019.02950

\section{Silicate Fertilizer Amendment Alters Fungal Communities and Accelerates Soil Organic Matter Decomposition}

\author{
Suvendu Das', Jeong Gu Lee'2, Song Rae Cho' ${ }^{2}$ Hyeon Ji Song² and Pil Joo Kim 1,2* \\ 1 Institute of Agriculture and Life Sciences, Gyeongsang National University, Jinju, South Korea, ${ }^{2}$ Division of Applied Life \\ Sciences, Gyeongsang National University, Jinju, South Korea
}

Soil microorganisms play a crucial role in organic matter decomposition and nutrient cycling in cropping systems. Compared to bacteria, fungal community composition and the role of fungi in organic matter decomposition and nutrient cycling in agro-systems are, however, elusive. Silicon (Si) fertilization is essential to improve agronomic performance of rice. The effects of the Si fertilizer application on the soil fungal community composition and their contribution in soil organic matter (SOM) decomposition are not yet studied. We investigated the short-term (120 days) slag silicate fertilizer (SSF) amendment impacts on plant photosynthesis and soil biochemical changes, soil fungal communities (assessed by ITS amplicon illumina sequencing), hydrolytic and oxidase enzyme activities, $\mathrm{CO}_{2}$ emissions, and bacterial and fungal respiration in diverse eco-geographic races of rice (Oryza sativa L.), i.e., Japonica rice (O. sativa japonica) and Indica rice (O. sativa indica). The short-term SSF amendment significantly increased the relative abundance of saprotrophic fungi and accelerated organic matter decomposition. The increase in saprotrophic fungi was mostly attributed to greater labile $\mathrm{C}$ availability and Si availability. Higher organic matter decomposition was accompanied by an increase in both hydrolytic and oxidative enzyme activities in response to the SSF amendment. The stimulation of oxidative enzyme activities was explained by an increase in root oxidase activities and iron redox cycling, whereas stimulation of hydrolytic enzyme activities was explained by the greater labile $\mathrm{C}$ availability under SSF fertilization. We conclude that the short-term SSF amendment increases saprotrophic fungal communities and soil hydrolytic and oxidative enzyme activities, which in turn stimulates SOM mineralization and thus could have negative feedback impacts on soil $\mathrm{C}$ storage in submerged rice paddies.

Keywords: slag silicate fertilization, fungal communities, soil enzyme activities, illumina sequencing, rice paddy

\section{INTRODUCTION}

One of the central sustainability challenges for intensive agriculture is to increase the yield while decreasing environmental degradation. Rice (Oryza sativa L.) is the major staple food consumed by over half the world population. Rice is a silicon ( $\mathrm{Si}$ ) accumulating plant, which can accumulate Si above $10 \%$ of shoot dry weight (Meharg and Meharg, 2015). Silicon (Si) is recognized as an agronomically essential element for rice cultivation. Intensive rice cultivation to meet the food 
requirements of the growing population continually decreases $\mathrm{Si}$ content of paddy soils and thus degrades the soil and decreases rice yield (Sasaki et al., 2014). The application of $\mathrm{Si}$ fertilizer is therefore highly recommended for Si-poor soils for optimum plant performance and crop yield improvement. Further, with the rapid growth in iron/steel manufacture, the larger quantity of slag produced draws notice for the need for its use in an efficient way, such as in agriculture. The use of slag in agriculture not only mitigates environmental consequences raised due to the disposal of slag at landfill sites but also improves crop productivity (Gwon et al., 2018; Das et al., 2019b). Steel making slag has been commonly used in slag-based silicate fertilizer (SSF) manufacturing (Ito, 2015). The SSF is rich in $\mathrm{Si}, \mathrm{Ca}, \mathrm{P}, \mathrm{Mg}, \mathrm{Fe}$, and $\mathrm{Mn}$, but plant essential nutrients such as, $\mathrm{N}, \mathrm{P}$, and $\mathrm{K}$ contents in the SSF are low (Ito, 2015). It is therefore advisable to use the SSF along with a mineral/organic fertilizer that has significant amounts of $\mathrm{N}$, $\mathrm{P}$, and K. The SSF is generally applied to the soil to provide the $\mathrm{Si}$ benefits to the plant. Silicon preferentially deposited in plant epidermal tissues and improves tissue rigidity and increases biotic and abiotic stress resistance, thereby enhances plant growth and yield (Meharg and Meharg, 2015). However, due to its liming nature (rich in $\mathrm{CaO}$ content), the long-term SSF amendment could make the soil more alkaline, which in turn stimulate soil organic matter (SOM) decomposition (Castro et al., 2015). The application of SSF is, therefore, proposed to practice in interruption, when the soil Si content and the soil $\mathrm{pH}$ (<6.5) become low (Ali et al., 2009). In this context, evaluating the short-term effects of the SSF amendment in rice paddies would be informative.

Soil microorganisms are crucial in the functioning of healthy and productive ecosystems, playing a pivotal role in SOM degradation, nutrient acquisition, and plant immune response (van Wees et al., 2008; Jacoby et al., 2017). Changes in soil properties in response to soil amendments are linked to the shift in soil microbial communities that regulate ecosystem functions and plant growth and productivity (Jacoby et al., 2017). Like bacteria, fungi were also crucial for agricultural systems where they play vital roles in SOM decomposition, nutrient cycling, and plant growth (de Vries and Caruso, 2016). Moreover, saprotrophic fungi have a greater role to degrade the plant litter because of their relatively high efficiency to degrade lignocelluloses, and mycorrhizal fungi play a crucial role in plant growth by nutrient exchange in a symbiotic relationship (de Vries and Caruso, 2016). Compared to bacteria, the changes in fungal communities and their role in response to agricultural management practices are, however, less studied.

The SSF amendment may alter soil fungal diversity and increase fungal richness. This is based on the fact that adequate Si supply increases plant photosynthesis and above ground biomass (Detmann et al., 2012), which in turn increases belowground $\mathrm{C}$ allocation through root exudation and likely increases soil microorganisms, including fungi. Moreover, the increased root $\mathrm{C}$ availability and root biomass in response to the SSF amendment could increase colonization by mycorrhizal fungi, and adequate rhizodeposit $\mathrm{C}$ could allow more fungal taxa to persist, increasing fungal diversity (de Vries and Caruso,
2016). The increase in below-ground labile $C$ (easily decomposed root litter and exudates) likely alleviates $\mathrm{C}$ limitation and could allow more saprophytic fungi to colonize (de Vries and Caruso, 2016), which in turn could increase SOM decomposition under the SSF amendment. Further, as a rich source of iron, the SSF amendment in paddy soils may enhance iron redox transformation, which in turn may increase soil oxidative and hydrolytic enzyme activities and thus organic matter decomposition (Van Bodegom et al., 2005; Hall and Silver, 2013). There is evidence that Si not only increases plants' resistance against pathogens, but also decreases the prevalence of pathogenic fungi albeit the underlying mechanism is not known (Wang et al., 2017). Silicon application is a preventive measure against a number of fungal diseases (Wang et al., 2017). It is therefore assumed that as a rich source of $\mathrm{Si}$, the SSF application could decrease the abundance of pathogenic fungi. Based on these reasons, we hypothesize that the SSF amendment would (i) increase plant photosynthesis and C, Si, and Fe availability in soil, (ii) alter the soil fungal community structure and increase the relative abundance of saprophytic fungi, driven by higher labile $\mathrm{C}$ and $\mathrm{Si}$ availability, and (iii) enhance soil $\mathrm{C}$ degradation in terms of increased soil $\mathrm{C}$ fluxes, due to increasing hydrolytic (driven by greater labile carbon) and oxidative (driven by root oxidase activity and iron redox cycling) enzyme activities. To test the hypothesis, we evaluated the short-term SSF amendment effects on plant photosynthesis and soil biochemical changes, soil fungal community structure, hydrolytic and oxidase enzyme activities, $\mathrm{CO}_{2}$ emissions, and bacterial and fungal respiration in Japonica and Indica rice varieties. Multivariate analyses were conducted to link fungal community structure to soil and plant variables, soil enzyme activities, and $\mathrm{CO}_{2}$ emissions.

\section{MATERIALS AND METHODS}

\section{Experimental Design}

The greenhouse pot experiment was carried out at Gyeongsang National University $\left(36^{\circ} 51^{\prime} \mathrm{N}, 128^{\circ} 28^{\prime} \mathrm{E}\right)$, Jinju, South Korea. The soil used for the pot experiment was collected from the nearby paddy field that has not been amended with any fertilizer and/or manure. The soil was air dried, crushed, sieved $(0.5 \mathrm{~cm}$ sieve), homogenized and $14 \mathrm{~kg}$ soil was packed in Wagner pots $(0.24 \mathrm{~m}$ diameter and $0.3 \mathrm{~m}$ height) to bulk density of $1.2 \mathrm{~g} \mathrm{~cm}^{-3}$. The soil was fine-silty, mixed, mesic family of Typic Endoaquepts and have the following properties: $\mathrm{pH}$ (1:5 soil:water extract) 5.6 , total soil organic carbon (TOC) $25.8 \mathrm{~g} \mathrm{~kg}^{-1}$, total nitrogen (TN) $2.76 \mathrm{~g} \mathrm{~kg}^{-1}$, available phosphorous (AP) $0.76 \mathrm{~g} \mathrm{~kg}^{-1}$, and available Si $0.86 \mathrm{~g} \mathrm{~kg}^{-1}$. There were four treatments: (1) Japonica rice cultivated without SSF (JC), (2) Japonica rice cultivated with SSF (JS), (3) Indica rice cultivated without SSF (IC), and (4) Indica rice cultivated with SSF (IS). Two major eco-geographic variety of rice, i.e., Japonica ( $c v$ Dongjinbyeo) and Indica ( $c v \operatorname{Rc158})$ with the equal growth duration (120 days) were selected for the pot experiment. Rice seedling (25 days old) were transplanted with two seedlings per pot. The soil was flooded with water 3 days before transplanting. The water level 
of all pots was retained at about $5 \mathrm{~cm}$ above the soil surface during the entire cropping season. The mineral fertilizer was applied to all the pots at the rate of $\mathrm{N}-\mathrm{P}_{2} \mathrm{O}_{5}-\mathrm{K}_{2} \mathrm{O}=110-45-58$ $\mathrm{kg} \mathrm{ha}{ }^{-1}$ by using urea, fused superphosphate, and potassium chloride (Das et al., 2019a). Basal fertilizers broadcasted 1 day prior to transplanting were $55 \mathrm{~kg} \mathrm{~N} \mathrm{ha}^{-1}, 45 \mathrm{~kg} \mathrm{P}_{2} \mathrm{O}_{5} \mathrm{ha}^{-1}$, and $40 \mathrm{~kg} \mathrm{~K}_{2} \mathrm{O} \mathrm{ha}^{-1}$, while $22 \mathrm{~kg} \mathrm{~N}^{-1}$ and $18 \mathrm{~kg} \mathrm{~K}_{2} \mathrm{O} \mathrm{ha}^{-1}$ were broadcasted at the mid vegetative (tillering) stage, and 33 $\mathrm{kg} \mathrm{N} \mathrm{ha}^{-1}$ was broadcasted at the early reproductive (panicle initiation) stage. For SSF treatments, the SSF was amended at the rate of $2 \mathrm{Mg} \mathrm{ha}^{-1}, 3$ days prior to transplanting. The chemical composition of the SSF was provided in Supplementary Table S1. All chemical and SSF fertilizers were applied according to the Rural Development Administration farm management practice guideline for rice cultivation in South Korea (Rural Development Administration [RDA], 2010). Experiments were performed in triplicate.

\section{Sampling and Analysis}

Soil samples were collected at different growth stages of the crop, i.e., seedling (1-20 days), tillering (15-20 days), panicle initiation (15-20 days), heading (30 days), and ripening (30 days) for a 120 days rice crop. Soil redox potential (Eh) was measured using Eh meter (PRN-41, DKK-TOA CORPORATION, Tokyo) and soil $\mathrm{pH}$ was measured by a $\mathrm{pH}$ meter (Orion 3 star, Thermo Electron Corporation, United States). The readily mineralizable carbon (RMC) and nitrogen (Ninhydrin nitrogen, NRN) content of soil were estimated by the method previously described by Das and Adhya (2014). The SOC content was estimated at the harvesting stage by a dry combustion C/N analyzer (CHNS-932 Elemental Analyzer, Leco, United States). The photosynthetic rate of tagged leaf was estimated using a photosynthesis apparatus (CIRAS-2, PPSystems, United Kingdom) during 9:00 am to 10:00 am. Separate planted pots from each of the treatments were sacrificed for the analysis of root oxidase activity. The root oxidase activity was measured by $\alpha$-Naphthylamine oxidation method (Gutierrez et al., 2014). The soil pore-water was sampled using rhizosamplers (EcoTech ${ }^{\circledR}$, Germany) and collected in acid washed, $\mathrm{N}_{2}$ flushed, crimp sealed vials. Silicon (aqSi) and $\mathrm{Fe}(\mathrm{aqFe})$ in soil pore-water were quantified using inductively coupled plasma-optical emission spectrometry (ICP-OES) (Vista-MPX, Varian, Australia).

\section{Molecular Characterization of Fungi}

Microbial DNA was extracted from $0.5 \mathrm{~g}$ of freshly collected rhizosphere soil using a FastDNA SPIN kit for soil (MP Biomedicals, United States) following the manufacturer's guideline. For each treatment, DNA was extracted in triplicate and pooled to minimize extraction bias, and quantified using NanoDrop 1000 spectrophotometer (NanoDrop Technologies, Wilmington, DE, United States). PCR amplification was performed in a total volume of $50 \mu \mathrm{L}$ reaction mixture containing $10 \mathrm{ng}$ of template DNA, $10 \times$ AccuPrime PCR buffer II (including dNTPs) (Invitrogen, United States), 0.2 $\mathrm{U}$ AccuPrime High Fidelity Taq Polymerase, and $0.4 \mathrm{mM}$ of both forward and reverse primers. The primer pair used to amplify fungi was ITS3/ITS4 (Li et al., 2016). The paired Illumina adaptors were linked to the $5^{\prime}$ end of the forward and reverse primers. The PCR conditions to amplify fungal ribosomal internal transcribed spacers (ITS) consisted of an initial denaturation at $95^{\circ} \mathrm{C}$ for $8 \mathrm{~min}, 36$ cycles of denaturation at $95^{\circ} \mathrm{C}$ for $45 \mathrm{~s}$, annealing at $58^{\circ} \mathrm{C}$ for $45 \mathrm{~s}$ and elongation at $72^{\circ} \mathrm{C}$ for $1 \mathrm{~min}$ followed by a final elongation at $72^{\circ} \mathrm{C}$ for $8 \mathrm{~min}$. Each sample was amplified in triplicates, pooled, gel purified using AxyPrep DNA Gel Extraction Kit (Axygen Biosciences, CA, United States), and quantified. To reduce PCR bias and to minimize PCR drift, three replicates PCR amplification was conducted. The amplicons were combined in equimolar amounts and paired-end sequenced $(2 \times 250)$ on an Illumina MiSeq platform (Illumina Inc., San Diego, CA, United States). Low quality reads (i.e., reads with any ambiguous bases, mismatches to primers, homopolymers longer than $8 \mathrm{bp}$, or less than $300 \mathrm{bp}$ in length) were removed using QIIME pipeline (Caporaso et al., 2012). Processed sequences with an identity threshold of $97 \%$ were clustered into OTUs. Taxonomy was assigned using the BLAST algorithm against the UNITE database (Li et al., 2016). Alpha diversity metrics were calculated based on rarefied OTU tables in QIIME. In addition, the OTUs were assigned to the fungal functional guild (mostly saprotrophs, pathotrophs, and symbiotrophs) using the FUNGuild annotation tool (Nguyen et al., 2016). Sequences were uploaded to the National Center for Biotechnology Information (NCBI) Sequence Read Archive under BioProject PRJNA491385.

\section{Soil Enzyme Assays}

Freshly collected rhizosphere soil samples at the harvesting stages of rice were used to study soil enzyme activities. The plant was uprooted from the pot, shaken to remove excess soils on roots, and soils adhering to roots were washed with sterile distilled water and centrifuged at $10000 \times g$ for $10 \mathrm{~min}$ to collect rhizosphere soils (Yergeau et al., 2014). The activities of hydrolytic enzymes [ $\alpha$-glucosidase (EC 3.2.1.20), $\beta$-1,4-glucosidase (EC 3.2.1.21), $\beta$-1,4-xylosidase (EC 3.2.1.37), and cellobiohydrolase (CBH; EC 3.2.1.91)] were measured by the microplate flurometric method, whereas oxidase enzyme [Phenol oxidase (EC 1.10.3.2) and peroxidase (EC 1.11.1.7)] activities were colorimetrically estimated using 96-well microplate according to the methods reported by Liu et al. (2017).

\section{$\mathrm{CO}_{2}$ Emissions and $\mathrm{C}$ Mineralization Using Selective Inhibitors}

Carbon dioxide emission fluxes during the rice cropping period were estimated following the close static chamber method as described by Gwon et al. (2018). The $\mathrm{CO}_{2}$ production from the soil (0-15 cm depth) was estimated by placing the moist soil sample $(20 \mathrm{~g})$ in a sterile serum bottle (volume $=120 \mathrm{~mL}$ ). The bottle was closed with neoprene septa, crimp-sealed, and incubated at $28^{\circ} \mathrm{C}$ in the dark. The $\mathrm{CO}_{2}$ production was estimated at every 3 days interval for 3 weeks by a gas chromatography (Shimadzu, GC-2010, Japan) equipped with a thermal conductivity detector (Gwon et al., 2018). 
The contribution of fungal or bacterial decomposition $\left(\mathrm{CO}_{2}\right.$ production) was determined in soil incubation experiments by selective inhibition with added Streptomycin sulfate (a bactericide) or Cycloheximide (a fungicide) (Ananyeva et al., 2010; Seo and DeLaune, 2010). Streptomycin sulfate was added to soils at $3.0 \mathrm{mg} \mathrm{g}^{-1}$, while Cycloheximide was added to soils at $1.5 \mathrm{mg} \mathrm{g}^{-1}$. Optimal inhibitor concentrations were determined using a preliminary screening experiment based on the criteria of Anderson and Domsch (1975). Additional details in methodology are given in the Supplementary Material.

\section{Statistical Analysis}

The treatment effects (SSF and cultivar) on the measured parameters were tested using two-way analyses of variance (ANOVA) according to the general linear model. The Post hoc comparison was performed by Tukey's honestly significant difference (HSD) test. The difference in fungal community composition (Bray-Curtis dissimilarities) was assessed by permutational multivariate analysis of variances (PERMANOVA). To demonstrate the changes in relative abundance of fungi, the response ratio (RR) was estimated and to determine whether the RR was significantly different from zero, one-sample $t$-test was conducted. The relationship between the soil fungal community and soil/plant variables, soil enzyme activities, and $\mathrm{CO}_{2}$ emissions were assessed by conducting mantel test, and canonical correspondence analysis (CCA). The analyses were conducted using the vegan package (v. 1.15-1) of $\mathrm{R}$ software (v. 2.8.1) (Oksanen et al., 2013).

\section{RESULTS}

\section{Soil Biochemical Properties and Photosynthetic Rate}

The SSF application significantly $(P<0.05)$ increased soil $\mathrm{pH}$, whereas soil Eh was not significantly influenced in both Japonica and Indica rice (Supplementary Figure S1 and Supplementary Table S2). The soil RMC content was significantly $(P<0.05)$ increased, but the soil NRN content was significantly $(P<0.05)$ decreased at maximum tillering (42 DAT), heading (75 DAT), and harvesting (120 DAT) stages of rice, in response to the SSF application (Supplementary Figure S1). On an average, 40.5 and $44.0 \%$ increase in soil RMC content, 15.3 and $15.8 \%$ decrease in soil NRN content in Japonica and Indica rice, respectively, were observed. The plant photosynthetic rate and root oxidase activity were significantly $(P<0.05)$ increased as a result of the SSF amendment in different plant growth stages of rice, irrespective of cultivar variation (Supplementary Figure S1). The photosynthetic rate was increased by 25.4 and $27.7 \%$ and the root oxidase activity was increased by 19.2 and $23.0 \%$ in Japonica and Indica rice. In comparison to no amended control, the SSF amendment significantly $(P<0.05)$ increased aqSi by 515 and $443 \%$, and aqFe by 39.6 and $76.7 \%$ in Japonica and Indica rice, respectively (Supplementary Figure S1 and Supplementary Table S2). The grain yield, straw biomass, and root biomass were significantly $(P<0.05)$ increased by 17.9 and $15.3 \%, 25.1$ and $36.8 \%$, and 10.9 and $15.3 \%$ in the SSF amended
Japonica and Indica cultivars, respectively, corresponding to no amended control.

\section{Fungal Community Diversity}

Rarefaction curves of the observed species and Chaol were used to assess whether the sequencing depth of the samples was adequate to signify the fungal communities in paddy soils. All rarefaction curves are quite smooth (Supplementary Figure S2), which showed that the sequencing depth adequately covers the diversity (Li et al., 2016). Further, Good's coverage was high on average (mean $=0.99$ ) indicating that fungal communities were sufficiently sampled. The number of reads sequenced from soil samples ranged from 151052 to 174372 (Supplementary Table S3). The proportion of high-quality reads ranged from 95.21 to $95.612 \%$ (Supplementary Table S3). The number of OTUs ranged from 426 to 521, and significantly $(P<0.05)$ increased by the SSF amendment (Figure 1). The number of fungal OTUs observed in our study was more similar to the fungal OTUs observed in other submerged paddy ecosystems (Yuan et al., 2018; Zhang et al., 2019).

The SSF amendment significantly $(P<0.5)$ increased fungal species richness (Chaol) and diversity (Shannon index) compared to the unamended control in both Japonica and Indica rice (Figure 1). However, no significant variation of the measured diversity indices within cultivars was found. Principal coordinate analysis (PCoA) based on fungal OTUs showed a clear difference in the fungal community structure between SSF amended and unamended treatments, irrespective of the rice cultivar (Figure 2). The first two principal coordinates explained $69.1 \%$ of the total variance of the fungal community.

Soil fungal communities were dominated by phylum Ascomycota $(4.6-15.6 \%)$ in all the treatments. Next to Ascomycota, the other two abundant phyla were Basidiomycota (1.0-2.2\%), and Chytridiomycota $(0.17-0.92 \%)$. All the three phyla were significantly increased by the SSF application, regardless of the rice cultivar (Figure 3 and Supplementary Table S4). Eurotiomycetes (1.3-5.6\%), Sordariomycetes (1.3$4.0 \%)$, Agaricomycetes (1.0-2.1\%), Dothideomycetes (0.4-2.0\%), Leotiomycetes (0.2-4.3\%), and Chytridiomycetes (0.2-1.0\%) were the five most abundant classes, whereas Agaricales (0.9-1.9\%), Sordariales (0.5-2.1\%), Eurotiales (0.7-2.9\%), Onygenales (0.7-2.7\%), and Hypocreales (0.6-1.7\%) were the five most abundant orders in all sequences. The SSF amendment significantly increased most of the abundant fungal classes and orders in both the rice cultivars (Supplementary Table S4). Among the most abundant genera, Chrysosporium, Rhizophydium, Mortierella, Phialosimplex, Acremonium, Geomyces, Talaromyces, Arthrobotrys, and Williopsis were considerably $(P<0.05)$ greater in the SSF amended treatments compared to unamended treatments, irrespective of rice cultivars (Figure 3 and Supplementary Table S4). The analysis of the fungal functional ecological guild revealed that saprotrophs dominated in the paddy soil, followed by pathotrophs and symbiotrophs (Figure 4). The SSF amendment significantly increased the relative abundance of saprotrophic fungi $(P<0.01)$, whereas the shift in symbiotrophic and pathotrophic fungi were not significant. 

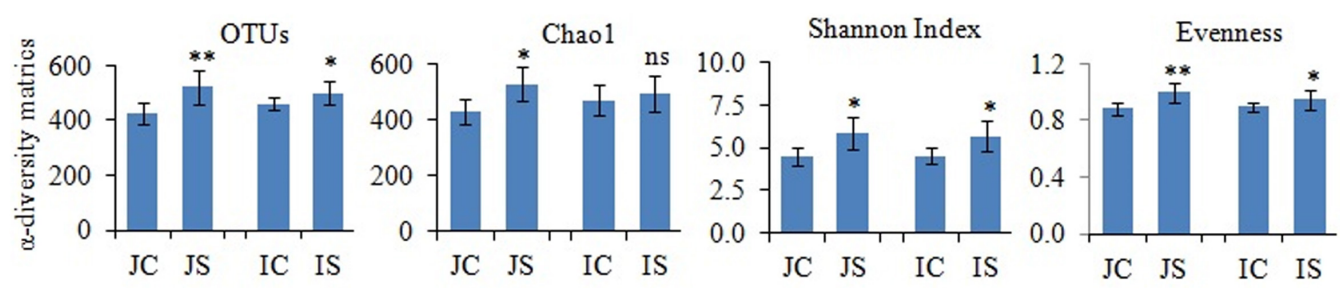

FIGURE 1 | The slag silicate fertilizer (SSF) effects on fungal $\alpha$-diversity indices. Significant difference between control and SSF within different cultivars were tested by two-tailed paired $t$-tests as indicated by * when $P<0.05$ and ** when $P<0.01$. JC, Japonica rice cultivated without SSF; JS, Japonica rice cultivated with SSF; IC, Indica rice cultivated without SSF; IS, Indica rice cultivated with SSF.

\section{Soil Enzyme Activities}

In comparison to unamended control, the SSF amendment significantly $(P<0.05)$ increased both hydrolytic (i.e., $\alpha$-glucosidase, $\quad \beta$-1,4-glucosidase, $\quad \beta$-1,4-xylosidase, $\quad$ and cellobiohydrolase) and oxidase (i.e., phenol oxidase and peroxidase) enzyme activities, irrespective of the cultivar (Figure 5). The cultivar effect on the measured soil enzyme activities was not significant (Supplementary Table S2).

\section{SOC, $\mathrm{CO}_{2}$ Emissions, and Bacterial and Fungal Respiration}

The changes in SOC content in response to the SSF amendment were not significant, irrespective of the cultivar (Figure 6 and Supplementary Table S2). The SSF amendment significantly $(P<0.05)$ increased cumulative $\mathrm{CO}_{2}$ emissions by 23.2 and $29.0 \%$ (Figure 6), whereas the cumulative $\mathrm{CO}_{2}$ production was significantly $(P<0.05)$ increased by 25.5 and $29.4 \%$ in Japonica and Indica rice, respectively, in comparison to no amended control (Figure 7). The application of the bactericide Streptomycin sulfate resulted in about $57.0 \%$ lowering of the cumulative $\mathrm{CO}_{2}$ production, whereas the application of the fungicide Cycloheximide resulted in about 28\% lowering of the cumulative $\mathrm{CO}_{2}$ production in comparison to the treatment to which no inhibitor had been added (Figure 7). The SSF amendment also significantly $(P<0.05)$ increased bacterial cumulative $\mathrm{CO}_{2}$ production (soil treated with Cycloheximide) by 36.3 and $39.0 \%$ and fungal cumulative $\mathrm{CO}_{2}$ production (soil treated with Streptomycin) by 30.8 and $33.3 \%$ in Japonica and Indica rice, in comparison to no amended control (Figure 7). The cultivar effects on $\mathrm{CO}_{2}$ emissions, cumulative $\mathrm{CO}_{2}$ production, and bacterial and fungal cumulative $\mathrm{CO}_{2}$ production were not significant (Supplementary Table S2).

\section{Linking Soil Fungal Communities to Soil and Plant Variables, Soil Enzyme Activities, $\mathrm{CO}_{2}$ Emissions, and Fungal $\mathrm{CO}_{2}$ Production}

Canonical correspondence analysis analyses and mantel test revealed that the soil $\mathrm{RMC}$ content, aqSi, aqFe, soil $\mathrm{pH}$, and root oxidase activity were significantly correlated with the fungal community (Figure 8 and Supplementary Table S6). Among the studied soil and plant factors, RMC $(r=0.293, P=0.001)$ had

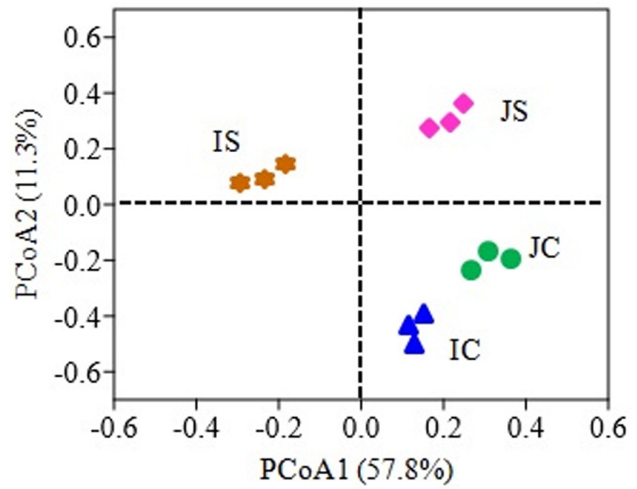

FIGURE 2 | Principal coordinate analysis (PCoA) plot based on the fungal OTUs for Japonica and Indica rice cultivated with and without slag silicate fertilizer (SSF). JC, Japonica rice cultivated without SSF; JS, Japonica rice cultivated with SSF; IC, Indica rice cultivated without SSF; IS, Indica rice cultivated with SSF.

the strongest positive correlation with the fungal community, followed by aqSi $(r=0.203, P=0.010)$, aqFe $(r=0.168$, $P=0.031)$, and soil $\mathrm{pH}(r=0.152, P<0.044)$, and root oxidase activity $(r=0.114, P=0.054)$ (Figure 8 and Supplementary Table S6). CCA analysis further showed that hydrolytic and oxidative enzyme activities, $\mathrm{CO}_{2}$ emissions, and fungal $\mathrm{CO}_{2}$ production significantly and positively correlated with the fungal community (Figure 8 and Supplementary Table S6). Among the top 12 abundant fungal genera, Chrysosporium, Rhizophydium, Mortierella, Phialosimplex, Acremonium, and Arthrobotrys showed significant and positive correlation with RMC content, aqSi, aqFe, soil $\mathrm{pH}$, root oxidase activity, soil enzyme activities, $\mathrm{CO}_{2}$ emissions, and fungal $\mathrm{CO}_{2}$ production (Figure 8).

\section{DISCUSSION}

In accordance with our hypothesis, the increased belowground carbon (e.g., RMC content) availability, aqSi and aqFe concentrations, and soil $\mathrm{pH}$ altered the soil fungal community structure in general, and increased the relative abundance of the saprotrophic fungal community in particular, in response to the SSF amendment. It is suggested that an increase in $\mathrm{Si}$ availability increases mesophyll conductance, which in turn 


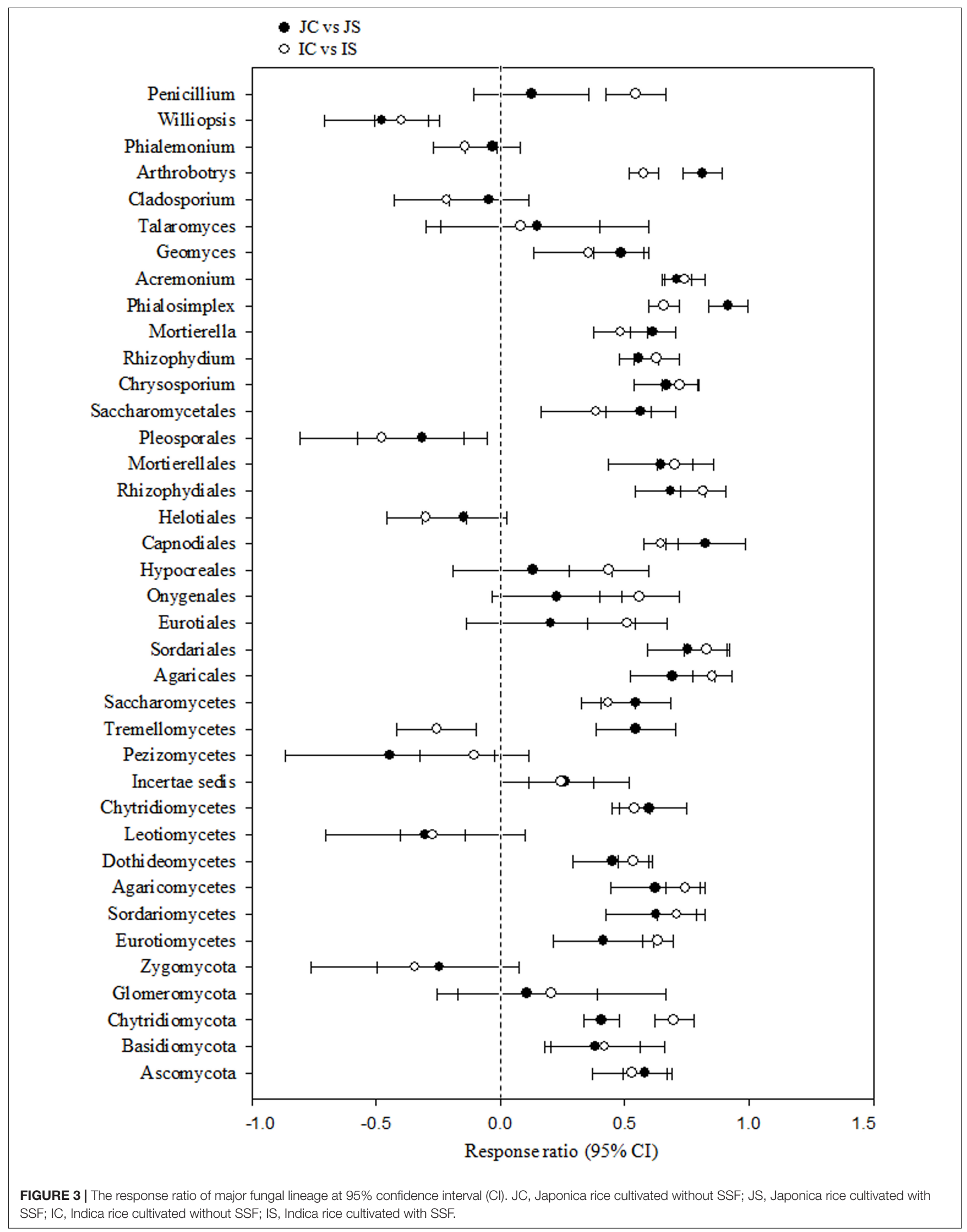




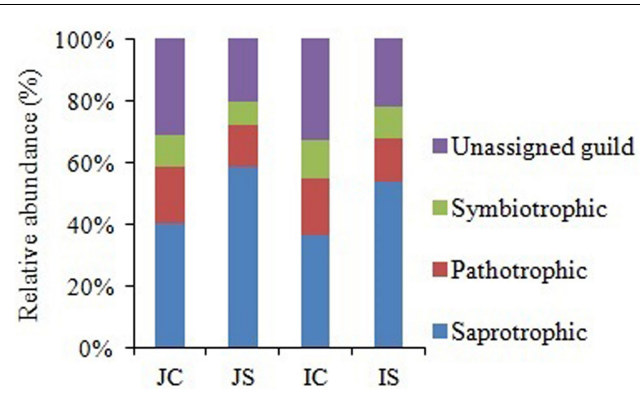

FIGURE 4 | The relative abundance of fungal functional guild in Japonica and Indica rice in response to the SSF amendment. JC, Japonica rice cultivated without SSF; JS, Japonica rice cultivated with SSF; IC, Indica rice cultivated without SSF; IS, Indica rice cultivated with SSF.

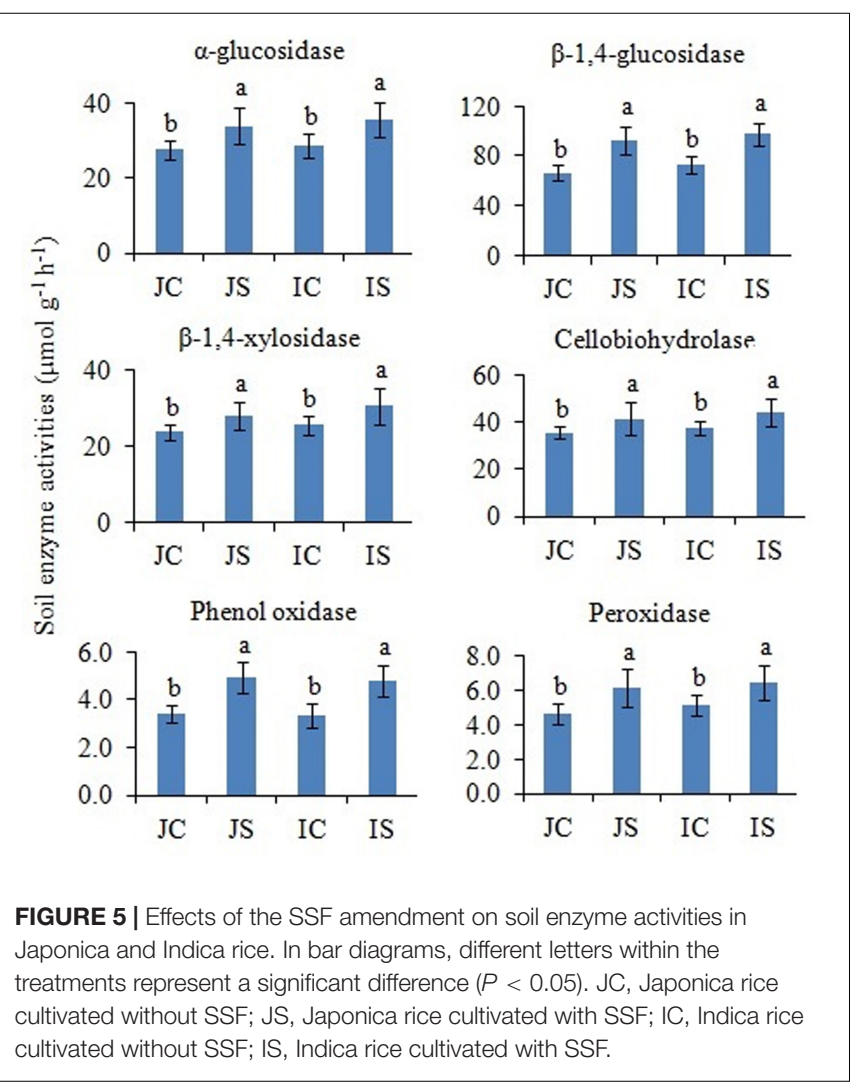

improves plant photosynthesis (Detmann et al., 2012). As a rich source of $\mathrm{Si}$, the SSF amendment significantly increased $\mathrm{Si}$ concentration in soil pore-water and thus plant photosynthesis. The increase in plant photosynthesis enhances root exudates which form continuous and highly dynamic $\mathrm{C}$ source and are the key component of the labile C pool in soils (Jacoby et al., 2017). The classical food web model postulates that increased labile C favors bacterial proliferation (de Vries and Caruso, 2016). We found, the short-term (120 days) SSF amendment remarkably increased both bacterial and fungal richness and diversity in a submerged rice cropping system (Das et al., 2019a). In recent years, a large number of studies revealed that labile $\mathrm{C}$ not only
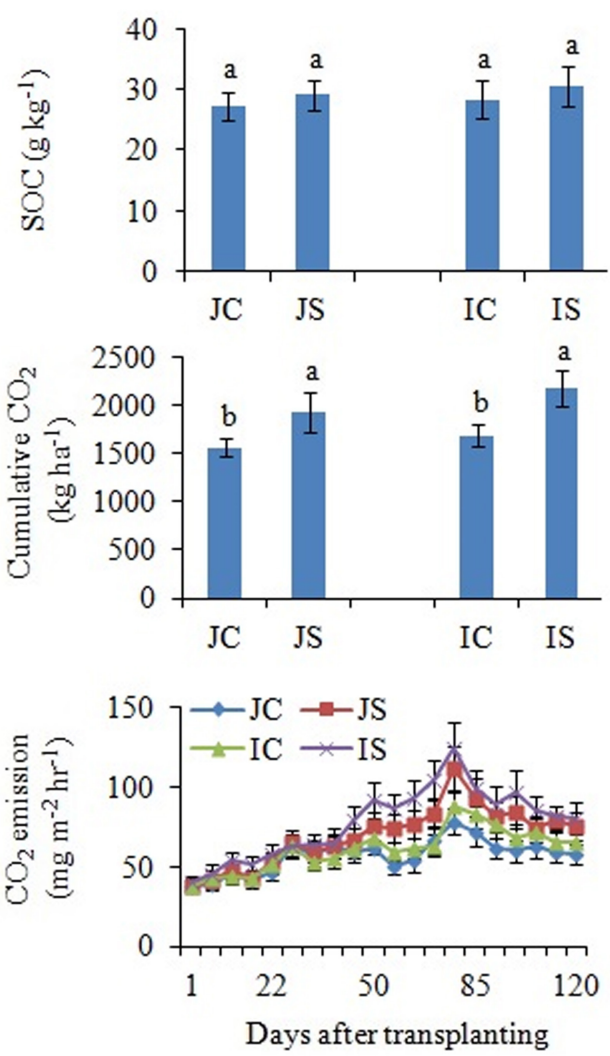

FIGURE 6 | Effects of the SSF amendment on SOC content, cumulative $\mathrm{CO}_{2}$ emissions, and $\mathrm{CO}_{2}$ emission rate from Japonica and Indica rice. In bar diagrams, different letters within the treatments represent a significant difference $(P<0.05)$. JC, Japonica rice cultivated without SSF; JS, Japonica rice cultivated with SSF; IC, Indica rice cultivated without SSF; IS, Indica rice cultivated with SSF.

help bacterial proliferation, but also the fungal proliferation at the same extent and saprotrophic fungi consume more labile C than previously suggested (de Vries and Caruso, 2016). In this study, the striking changes in fungal community composition were a significant increase in the most dominant classes Agaricales and Sordariales, in which the majority of the species are saprotrophic (Klaubauf et al., 2010), and the increase in the relative abundance of dominant genera Chrysosporium, Rhizophydium, Mortierella, Phialosimplex, Acremonium, and Arthrobotrys under SSF fertilization. The members of these genera mostly include fast growing saprotrophs that mainly utilize simple soluble carbon (Klaubauf et al., 2010; Vořrišková et al., 2014; Anthony et al., 2017). The dominant species, Chrysosporium keratinophilum, Mortierella polycephala, Agaricales sp., Helotiales sp., Phialemonium inflatum, and Aspergillus sydowii, which are saprotrophic fungi and widely found in soil habitats, noticeably increased in response to the SSF amendment (Supplementary Table S5). Saprotrophic fungi ( $r$-selected) proliferate in the presence of easily accessible C source and photosynthetic $\mathrm{C}$ allocation to roots can stimulate the proliferation of saprotrophic fungi (Anthony et al., 2017). The increase in soil RMC content and its significant and positive 

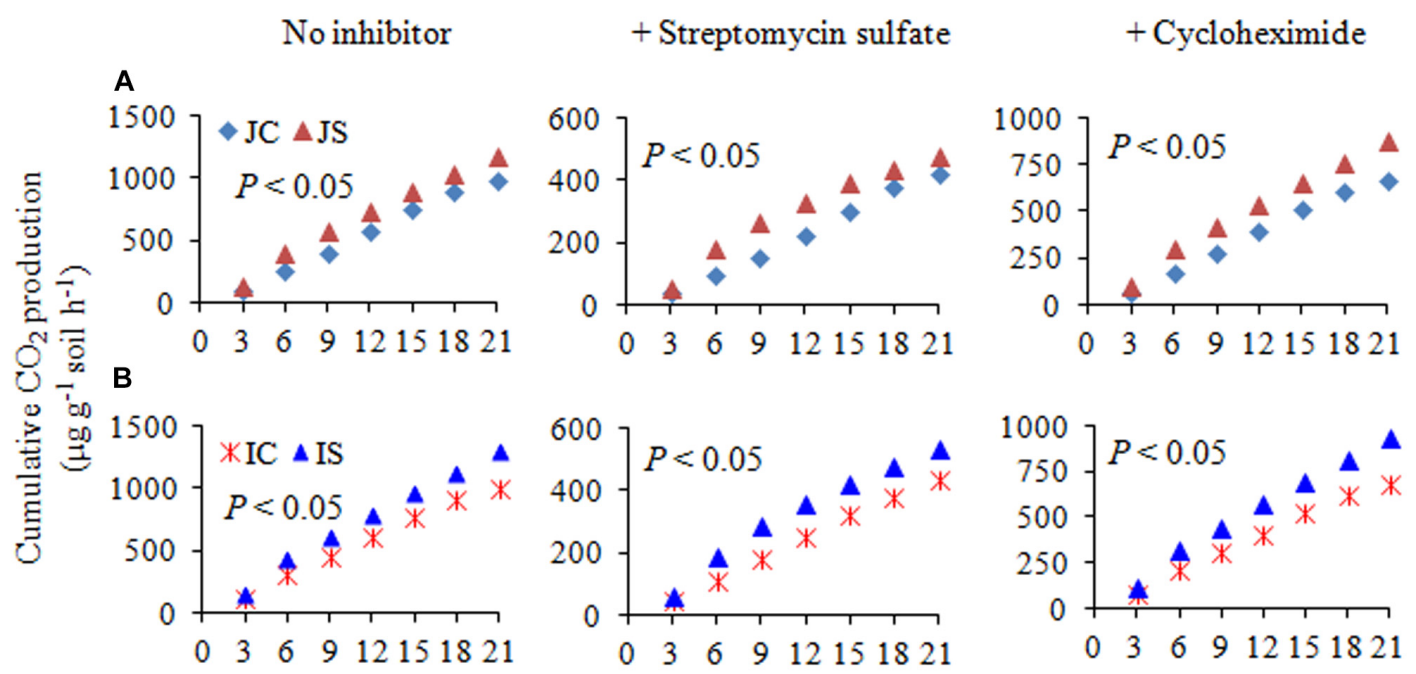

\section{Days of incubation}

FIGURE 7 | The cumulative $\mathrm{CO}_{2}$ production with no inhibitor, +streptomycin sulfate, and +cycloheximide in (A) Japonica and (B) Indica paddy soil. JC, Japonica rice cultivated without SSF; JS, Japonica rice cultivated with SSF; IC, Indica rice cultivated without SSF; IS, Indica rice cultivated with SSF. Bacterial and fungal cumulative $\mathrm{CO}_{2}$ production was estimated from the soil treated with cycloheximide and streptomycin sulfate, respectively.
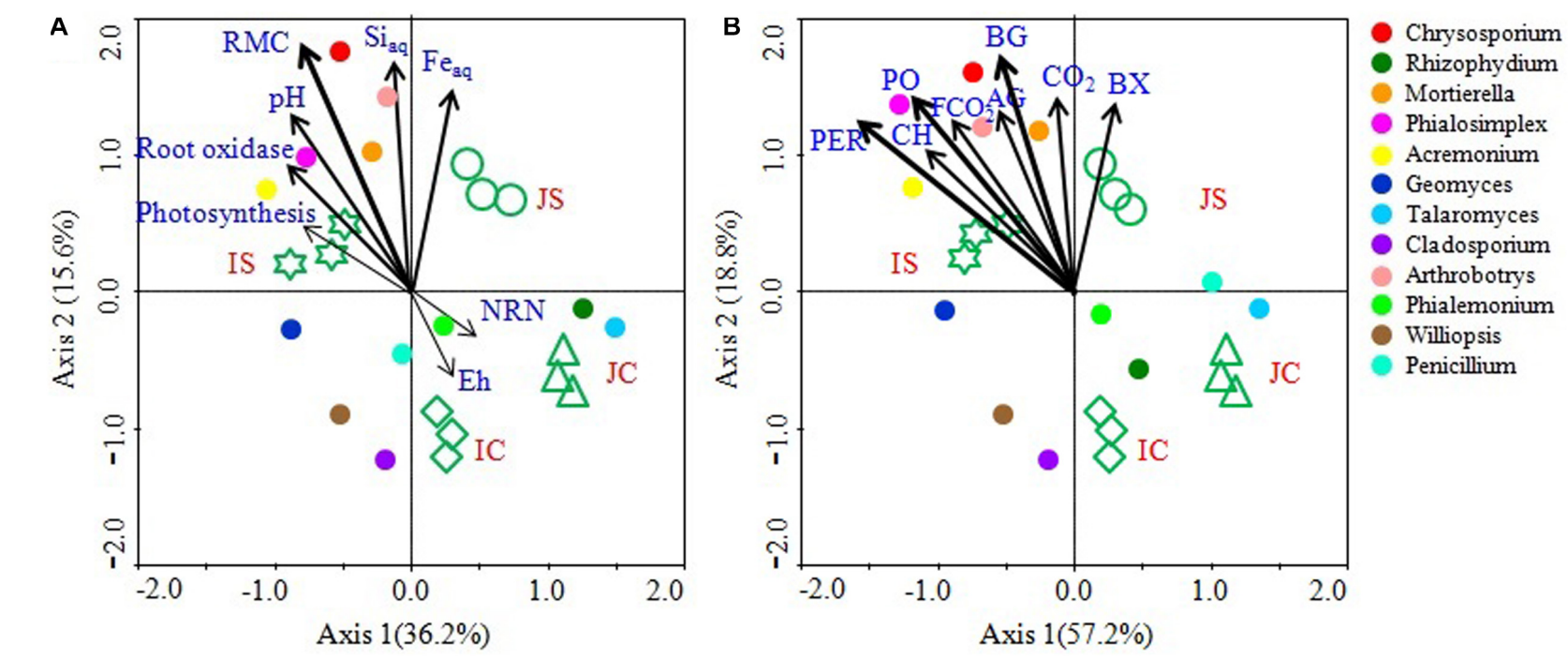

FIGURE 8 | Canonical correspondence analysis (CCA) showing linkage of the top 12 fungal genera and soil and plant parameters (A) and soil enzyme activities, CO emission, and fungal $\mathrm{CO}_{2}$ production (B). The lengths of these arrows indicate the relative importance of measured variables, whereas the angle between the arrows and the axis reflects the degree to which they are correlated. To statistically evaluate the significance $(P<0.01)$ of the first canonical axis and of all canonical axes together, the Monte Carlo permutation full model test with 999 unrestricted permutations was performed. RMC, Readily mineralizable carbon; NRN, Ninhydrin nitrogen; AG, $\alpha$-glucosidase; BG, $\beta$-1,4-glucosidase; BX, $\beta$-1,4-xylosidase; $\mathrm{CH}$, Cellobiohydrolase; $\mathrm{PO}$, Phenol oxidase; PER, Peroxidase; $\mathrm{CO}_{2}$, $\mathrm{CO}_{2}$ emission; $\mathrm{FCO}_{2}$, Fungal $\mathrm{CO}_{2}$ production.

correlation with the dominant saprotrophic fungal genera advocates the proliferation of saprotrophic fungi driven by the labile C source in response to the SSF amendment. Further, the high Fe content in SSF likely increases Fe reduction in anaerobic environments and can enhance dissolved organic $\mathrm{C}$ (easily accessible $\mathrm{C}$ source) due to increased $\mathrm{pH}$ and colloid dispersion
(Buettner et al., 2014), which in turn can increase the population of saprotrophic fungi.

Silicon availability can increase the population of soil fungi. In this study, we found a significant and positive correlation between Si and fungal community. Wainwright et al. (1997) reported that $\mathrm{Si}$ compounds can increase fungal growth under 
both oligotrophic and nutrient-rich conditions. Several possible mechanisms underlying the stimulatory effects of Si on fungal growth have been proposed (Wainwright et al., 1997): (1) silicon compounds or the bioavailable form of Si (i.e., silicic acid) are efficient at absorbing nutrients from the soil, which then acted as nutrient sources for the growth of fungi, (2) silicic acid enhances hyphal growth and stimulates fungal spore germination, and (3) fungi can grow chemoautotrophically by using energy gained from Si metabolism. The molecular mechanism of the stimulatory effects of Si on fungal growth is not known. Notably, some dominant genera (e.g., Cladosporium, Phialemonium) and species (e.g., Phialosimplex caninus, Metarhizium anisopliae) of pathotrophic fungi did not change significantly in response to the SSF amendment (Supplementary Tables S4, S5). Nonetheless, Si application has been reported to increase the resistance of plants to pathogenic fungi, probably for its role in induced systematic resistance by increasing the production of stress hormones, or it can interfere with cation cofactors of enzymes influencing plant pathogenesis (Fauteux et al., 2005). The exact mechanism by which Si modulates plant signaling is, however, not known. The relative abundance of symbiotrophic fungal genera was low or negligible, likely due to the flooded conditions of rice paddies (Vallino et al., 2014).

The remarkable increase in saprotrophic fungal communities indicates its potential role in SOM decomposition under SSF fertilization, because, saprotrophic fungi are considered a key regulator of SOM decomposition and can contribute up to $90 \%$ of total heterotrophic respiration (Joergensen and Wichern, 2008). Noteworthy, many fungi could also promote soil carbon sequestration through the synthesis of recalcitrant substances and mostly the dominance of mycorrhizal fungal communities suggested an enhanced soil C sequestration (Wilson et al., 2009; $\mathrm{Xu}$ et al., 2017), whereas the saprophytic fungal dominance favored C degradation (Joergensen and Wichern, 2008; Wang et al., 2014). In this study, SOC content did not change in response to the short-term SSF amendment. SOC responds slowly to agricultural management practices, which implies that the changes in SOC need many years to be detectable due to the substantial amount of SOC present in soil profile compared to the much smaller proportion of organic $C$ being stored or lost from the soil annually (Haddaway et al., 2015). In comparison to the unamended control, the SSF amendment significantly increased $\mathrm{CO}_{2}$ production (SOC mineralization) and the fungal $\mathrm{CO}_{2}$ production was increased by $32.0 \%$. Studies conducted in upland arable soil using selective microbial inhibitors indicate that fungi dominate microbial biomass, and $\mathrm{CO}_{2}$ derived from the fungal decomposition of SOM dominates the $\mathrm{CO}_{2}$ evolved from soils (Joergensen and Wichern, 2008). Flooding the soil favors bacterial proliferation in comparison to the fungal proliferation and may be for this reason, in this study, bacterial contribution to the heterotrophic respiration is more, compared to the fungal respiration. Higher $\mathrm{CO}_{2}$ emissions from rice paddies further suggested both heterotrophic and autotrophic respiration increased under SSF fertilization. Saprotrophic fungi degrade SOM as a result of their ability to produce a wide range of extracellular enzymes (Vořrišková et al., 2014). Several dominant saprotrophic fungal genera showed significant and positive correlation with both hydrolytic and oxidative enzyme activities and $\mathrm{CO}_{2}$ emissions (Figure 8). The SSF amendment significantly increased both soil hydrolytic and oxidase enzyme activities. Soil enzymes are synthesized by microorganisms to degrade specific organic compounds by hydrolysis (hydrolytic enzymes) or oxidation (oxidative enzymes) (Burns et al., 2013). Generally, extracellular enzymes instigating the decomposition of SOM fractions are separated into two groups; hydrolytic enzymes (causing the decomposition of labile organic matter to gain nutrients for primary metabolism) and oxidative enzymes (causing the decomposition of recalcitrant organic matter for co-metabolic acquisition of nutrients) (Nannipieri et al., 2003; Burns et al., 2013). The higher labile carbon availability could increase hydrolytic enzyme activities (de Vries and Caruso, 2016), whereas a greater $\mathrm{O}_{2}$ availability, which is due to the higher root oxidase activity could increase oxidase enzyme activities in response to SSF fertilization. Oxygen availability apparently affects oxidase enzyme activities that require $\mathrm{O}_{2}$ as a substrate (Hall and Silver, 2013). Moreover, as a rich source of iron, the SSF amendment could increase phenol oxidase activities. There is evidence that ferrous iron increases phenol oxidase activity and organic matter decomposition in waterlogged conditions, probably due to the catalysis of additional $\mathrm{OH}$ radical production, promoting the oxidation of phenolics (Van Bodegom et al., 2005). Hall and Silver (2013) reported that amending soils with ferrous iron at field concentrations stimulates shortterm C mineralization by up to $27.0 \%$. Hall et al. (2014) also demonstrated that hydrolytic enzyme activities increase with ferrous iron under anaerobic conditions, in contrast to the "enzyme latch" hypothesis. Ferrous iron availability under rhizospheric microaerophilic conditions in rice paddies could play a pivotal role in SOM decomposition since ferrous and ferric iron is the dominant redox couple in submerged rice cropping systems and decomposition of organic matter is a redox driven process (Kögel-Knabner et al., 2010). To achieve a deeper understanding of the role of fungi in SOM decomposition under SSF fertilization, it would be necessary, however, to complement the current data with a functional analysis of metatranscriptomes.

\section{CONCLUSION}

The slag silicate fertilizer (SSF) markedly increased the relative abundance of saprotrophic fungi, driven by higher labile carbon and Si availability. The SSF also increased soil carbon fluxes, due to increasing hydrolytic and oxidative enzyme activities. Yet, the mechanisms for increasing enzyme activities are different: hydrolytic enzymes were driven by greater labile carbon while oxidative enzymes were driven by root oxidase activity and iron redox cycling. Overall, the SSF amendment alters fungal communities and enzyme activities, and accelerates SOM decomposition, indicating a potential soil carbon loss in the rice fields. Long-term field studies with diverse soil and climate conditions are essential to shed light on the soil microbial behavior and their cascade effects on carbon sequestration under SSF fertilization in rice cropping systems. 


\section{DATA AVAILABILITY STATEMENT}

The datasets generated for this study can be found in the BioProject PRJNA491385.

\section{AUTHOR CONTRIBUTIONS}

$\mathrm{SD}$ designed the research, analyzed the data, and wrote the first draft of the manuscript. SD, JL, SC, and HS conducted the experiments. All authors contributed to the intellectual input and assistance to this study and manuscript preparation.

\section{REFERENCES}

Ali, M. A., Lee, C. H., Lee, Y. B., and Kim, P. J. (2009). Silicate fertilization in no-tillage rice farming for mitigation of methane emission and increasing rice productivity. Agric. Ecosyst. Environ. 132, 16-22. doi: 10.1016/j.agee.2009.02. 014

Ananyeva, N. D., Stolnikova, E. V., Susyan, E. A., and Khodzhaeva, A. K. (2010). The fungal and bacterial biomass (selective inhibition) and the production of $\mathrm{CO}_{2}$ and $\mathrm{N}_{2} \mathrm{O}$ by soddy-podzolic soils of postagrogenic biogeocenoses. Eurasian Soil Sci. 43, 1287-1293. doi: 10.1134/S1064229310110128

Anderson, J. P. E., and Domsch, K. H. (1975). Measurement of bacterial and fungal contributions to respiration of selected agricultural and forest soils. Can. J Microbiol. 21, 314-322. doi: 10.1139/m75-045

Anthony, M. A., Frey, S. D., and Stinson, K. A. (2017). Fungal community homogenization, shift in dominant trophic guild, and appearance of novel taxa with biotic invasion. Ecosphere 8:e1951. doi: 10.1002/ecs2.1951

Buettner, S. W., Kramer, M. G., Chadwick, O. A., and Thompson, A. (2014). Mobilization of colloidal carbon during iron reduction in basaltic soils. Geoderma 221, 139-145. doi: 10.1016/j.geoderma.2014.01.012

Burns, R. G., DeForest, J. L., Marxsen, J., Sinsabaugh, R. L., Stromberger, M. E., Wallenstein, M. D., et al. (2013). Soil enzymes in a changing environment: current knowledge and future directions. Soil Biol. Biochem. 58, 216-234. doi: 10.1016/j.soilbio.2012.11.009

Caporaso, J. G., Lauber, C. L., Walters, W. A., Berg-Lyons, D., Huntley, J., Fierer, N., et al. (2012). Ultra-high-throughput microbial community analysis on the Illumina HiSeq and MiSeq platforms. ISME J. 6:1621. doi: 10.1038/ismej.2012.8

Castro, G. S. A., Crusciol, C. A. C., Calonego, J. C., and Rosolem, C. A. (2015). Management impacts on soil organic matter of tropical soils. Vadose Zone J. 14, 1-8. doi: 10.2136/vzj2014.07.0093

Das, S., and Adhya, T. K. (2014). Effect of combine application of organic manure and inorganic fertilizer on methane and nitrous oxide emissions from a tropical flooded soil planted to rice. Geoderma 213, 185-192. doi: 10.1016/j.geoderma. 2013.08.011

Das, S., Gwon, H. S., Khan, M. I., Van Nostrand, J. D., Alam, M. A., and Kim, P. J. (2019a). Taxonomic and functional responses of soil microbial communities to slag-based fertilizer amendment in rice cropping systems. Environ. Int. 127, 531-539. doi: 10.1016/j.envint.2019.04.012

Das, S., Kim, G. W., Hwang, H. Y., Verma, P. P., and Kim, P. J. (2019b). Cropping with slag to address soil, environment, and food security. Front. Microbiol. 10:1320. doi: 10.3389/fmicb.2019.01320

de Vries, F. T., and Caruso, T. (2016). Eating from the same plate? Revisiting the role of labile carbon inputs in the soil food web. Soil Biol. Biochem. 102, 4-9. doi: 10.1016/j.soilbio.2016.06.023

Detmann, K. C., Araújo, W. L., Martins, S. C., Sanglard, L. M., Reis, J. V., Detmann, E., et al. (2012). Silicon nutrition increases grain yield, which, in turn, exerts a feed-forward stimulation of photosynthetic rates via enhanced mesophyll conductance and alters primary metabolism in rice. New Phytol. 196, 752-762. doi: $10.1111 /$ j.1469-8137.2012.04299.x

Fauteux, F., Rémus-Borel, W., Menzies, J. G., and Bélanger, R. R. (2005). Silicon and plant disease resistance against pathogenic fungi. FEMS Microbiol. Lett. 249, 1-6. doi: 10.1016/j.femsle.2005.06.034

\section{FUNDING}

This work was supported by the Basic Science Research Program through the National Research Foundation of Korea (NRF) funded by the Ministry of Education (NRF2015R1A6A1A03031413).

\section{SUPPLEMENTARY MATERIAL}

The Supplementary Material for this article can be found online at: https://www.frontiersin.org/articles/10.3389/fmicb. 2019.02950/full\#supplementary-material

Gutierrez, J., Atulba, S. L., Kim, G., and Kim, P. J. (2014). Importance of rice root oxidation potential as a regulator of $\mathrm{CH}_{4}$ production under waterlogged conditions. Biol. Fertil. Soils 50, 861-868. doi: 10.1007/s00374-014-0904-0

Gwon, H. S., Khan, M. I., Alam, M. A., Das, S., and Kim, P. J. (2018). Environmental risk assessment of steel-making slags and the potential use of LD slag in mitigating methane emissions and the grain arsenic level in rice (Oryza sativa L.). J. Hazard. Mater. 353, 236-243. doi: 10.1016/j.jhazmat.2018.04.023

Haddaway, N. R., Hedlund, K., Jackson, L. E., Kätterer, T., Lugato, E., Thomsen, I. K., et al. (2015). What are the effects of agricultural management on soil organic carbon in boreo-temperate systems? Environ. Evid. 4:23. doi: 10.1186/ s13750-015-0049-0

Hall, S. J., and Silver, W. L. (2013). Iron oxidation stimulates organic matter decomposition in humid tropical forest soils. Glob. Change Biol. 19, 2804-2813. doi: $10.1111 /$ gcb. 12229

Hall, S. J., Treffkorn, J., and Silver, W. L. (2014). Breaking the enzymatic latch: impacts of reducing conditions on hydrolytic enzyme activity in tropical forest soils. Ecology 95, 2964-2973. doi: 10.1890/13-2151.1

Ito, K. (2015). Steelmaking slag for fertilizer usage. Nippon steel and Sumitomo metal technical report No. 109. Available at: http://www.nssmc.com/en/tech/report/ nssmc/pdf/109-23.pdf

Jacoby, R., Peukert, M., Succurro, A., Koprivova, A., and Kopriva, S. (2017). The role of soil microorganisms in plant mineral nutrition-current knowledge and future directions. Front. Plant Sci. 8:1617. doi: 10.3389/fpls.2017.01617

Joergensen, R. G., and Wichern, F. (2008). Quantitative assessment of the fungal contribution to microbial tissue in soil. Soil Biol. Biochem. 40, 2977-2991. doi: 10.1016/j.soilbio.2008.08.017

Klaubauf, S., Inselsbacher, E., Zechmeister-Boltenstern, S., Wanek, W., Gottsberger, R., Strauss, J., et al. (2010). Molecular diversity of fungal communities in agricultural soils from Lower Austria. Fungal Divers. 44, 65-75. doi: 10.1007/s13225-010-0053-1

Kögel-Knabner, I., Amelung, W., Cao, Z., Fiedler, S., Frenzel, P., Jahn, R., et al. (2010). Biogeochemistry of paddy soils. Geoderma 157, 1-14. doi: 10.1016/j. geoderma.2010.03.009

Li, W., Wang, M., Bian, X., Guo, J., and Cai, L. (2016). A high-level fungal diversity in the intertidal sediment of Chinese seas presents the spatial variation of community composition. Front. Microbiol. 7:2098. doi: 10.3389/fmicb.2016. 02098

Liu, Z., Rong, Q., Zhou, W., and Liang, G. (2017). Effects of inorganic and organic amendment on soil chemical properties, enzyme activities, microbial community and soil quality in yellow clayey soil. PLoS One 12:e0172767. doi: 10.1371/journal.pone.0172767

Meharg, C., and Meharg, A. A. (2015). Silicon, the silver bullet for mitigating biotic and abiotic stress, and improving grain quality, in rice? Environ. Exp. Bot. 120, 8-17. doi: 10.1016/j.envexpbot.2015.07.001

Nannipieri, P., Ascher, J., Ceccherini, M., Landi, L., Pietramellara, G., and Renella, G. (2003). Microbial diversity and soil functions. Eur. J. Soil Sci. 54, 655-670. doi: 10.1046/j.1351-0754.2003.0556.x

Nguyen, N. H., Song, Z., Bates, S. T., Branco, S., Tedersoo, L., Menke, J., et al. (2016). FUNGuild: an open annotation tool for parsing fungal community datasets by ecological guild. Fungal Ecol. 20, 241-248. doi: 10.1016/j.funeco. 2015.06.006 
Oksanen, J., Blanchet, F. G., Kindt, R., Legendre, P., Minchin, P. R., O’hara, R. B., et al. (2013). Package 'vegan'. Community ecology package, version, 2(9). doi: 10.1016/j.funeco.2015.06.006

Rural Development Administration [RDA], (2010). Fertilization Standard of Crop Plants. Suwon: Rural Development Administration.

Sasaki, S. M., Kakuda, K., Sasaki, Y., and Ando, H. (2014). Effects of slag silicate fertilizer on silicon content of rice plants grown in paddy fields on the Shounai Plain, Yamagata, Japan. Soil Sci. Plant Nutr. 60, 708-721. doi: 10.1080/00380768. 2014.936305

Seo, D. C., and DeLaune, R. D. (2010). Effect of redox conditions on bacterial and fungal biomass and carbon dioxide production in Louisiana coastal swamp forest sediment. Sci. Total Environ. 408, 3623-3631. doi: 10.1016/j.scitotenv. 2010.04.043

Vallino, M., Fiorilli, V., and Bonfante, P. (2014). Rice flooding negatively impacts root branching and arbuscular mycorrhizal colonization, but not fungal viability. Plant Cell Environ. 37, 557-572. doi: 10.1111/pce.12177

Van Bodegom, P. M., Broekman, R., Van Dijk, J., Bakker, C., and Aerts, R. (2005). Ferrous iron stimulates phenol oxidase activity and organic matter decomposition in waterlogged wetlands. Biogeochemistry 76, 69-83. doi: 10. 1007/s10533-005-2053-x

van Wees, S. C. M., van der Ent, S., and Pieterse, C. M. J. (2008). Plant immune responses triggered by beneficial microbes. Curr. Opin. Plant Biol. 11, 443-448. doi: 10.1016/j.pbi.2008.05.005

Vořišková, J., Brabcová, V., Cajthaml, T., and Baldrian, P. (2014). Seasonal dynamics of fungal communities in a temperate oak forest soil. New Phytol. 201, 269-278. doi: 10.1111/nph.12481

Wainwright, M., Al-Wajeeh, K., and Grayston, S. J. (1997). Effect of silicic acid and other silicon compounds on fungal growth in oligotrophic and nutrient-rich media. Mycol. Res. 101, 933-938. doi: 10.1017/S0953756297003560

Wang, M., Gao, L., Dong, S., Sun, Y., Shen, Q., and Guo, S. (2017). Role of silicon on plant-pathogen interactions. Front. Plant Sci. 8:701. doi: 10.3389/fpls.2017. 00701
Wang, Q., Wang, S., He, T., Liu, L., and Wu, J. (2014). Response of organic carbon mineralization and microbial community to leaf litter and nutrient additions in subtropical forest soils. Soil Biol. Biochem. 71, 13-20. doi: 10.1016/j.soilbio. 2014.01.004

Wilson, G. W., Rice, C. W., Rillig, M. C., Springer, A., and Hartnett, D. C. (2009). Soil aggregation and carbon sequestration are tightly correlated with the abundance of arbuscular mycorrhizal fungi: results from long-term field experiments. Ecol. Lett. 12, 452-461. doi: 10.1111/j.1461-0248.2009.01303.x

Xu, M., Li, X., Cai, X., Li, X., Christie, P., and Zhang, J. (2017). Land use alters arbuscular mycorrhizal fungal communities and their potential role in carbon sequestration on the Tibetan Plateau. Sci. Rep. 7:3067. doi: 10.1038/s41598-01703248-0

Yergeau, E., Sanschagrin, S., Maynard, C., St-Arnaud, M., and Greer, C. W. (2014). Microbial expression profiles in the rhizosphere of willows depend on soil contamination. ISME J. 8, 344-358. doi: 10.1038/ismej.2013.163

Yuan, C., Zhang, L., Hu, H., Wang, J., Shen, J., and He, J. (2018). The biogeography of fungal communities in paddy soils is mainly driven by geographic distance. J. Soils Sediments 18, 1795-1805. doi: 10.1007/s11368-018-1924-4

Zhang, Y., Li, Q., Chen, Y., Dai, Q., and Hu, J. (2019). Mudflat reclamation causes change in the composition of fungal communities under long-term rice cultivation. Can. J. Microbiol. 65, 1-8. doi: 10.1139/cjm-2019-0005

Conflict of Interest: The authors declare that the research was conducted in the absence of any commercial or financial relationships that could be construed as a potential conflict of interest.

Copyright (c) 2019 Das, Lee, Cho, Song and Kim. This is an open-access article distributed under the terms of the Creative Commons Attribution License (CC BY). The use, distribution or reproduction in other forums is permitted, provided the original author(s) and the copyright owner(s) are credited and that the original publication in this journal is cited, in accordance with accepted academic practice. No use, distribution or reproduction is permitted which does not comply with these terms. 